\title{
O Impacto das Alterações Climáticas na Saúde
}

\section{The Impact of Climate Change on Health}

António TAVARES $\triangle 1,2$

Acta Med Port 2018 May;31(5):241-242 - https://doi.org/10.20344/amp.10473

Palavras-chave: Mudança Climática; Saúde Global; Tempo

Keywords: Climate Change; Global Health; Weather

Desde a formação do Sistema Solar, houve sempre mudanças no clima do planeta Terra. Contudo, há agora uma forte evidência de que, pela primeira vez, o clima na Terra está a mudar como resultado da atividade humana. Quer o aquecimento global, quer a depleção do ozono são influenciados pela atividade humana.

Os modelos preditivos do clima sugerem que as temperaturas médias poderão aumentar cerca de 1,4 a $5,8^{\circ} \mathrm{C}$ no final do século XXI.1,2 Prevê-se que os fenómenos climáticos extremos sejam mais frequentes e haja um aumento do nível do mar. ${ }^{3}$

Estas alterações climáticas podem ter efeitos diretos e indiretos na saúde, sendo uma das ameaças ambientais mais importantes neste século $X X I{ }^{2} A$ saúde pode ser afetada diretamente através de temperaturas extremas, designadamente ondas de calor ou vagas de frio, cheias e tempestades, secas, frequência aumentada de doenças de origem hídrica e alimentar e uma mudança de padrão nas doenças com origem em vetores e roedores. A saúde pode ser afetada indiretamente através da disrupção dos métodos de produção alimentar e da diminuição da produtividade económica.

Doenças e morte, alterações de saúde resultantes da poluição atmosférica, designadamente do foro cardiovascular e respiratório, efeitos na saúde mental, emergência de doenças infecto - contagiosas, impactos de desastres naturais e doenças relacionadas com alterações ambientais emergentes são consequências graves, a assinalar.

No que respeita às doenças infeciosas, as condições climáticas influenciam a transmissão de doenças com origem hídrica (qualidade e quantidade da água) e alimentar (quantidade de alimentos - com 3,1 milhões de mortos anualmente por desnutrição - e segurança alimentar) e o perfil de distribuição das doenças infeciosas, não só porque a temperatura afeta os ciclos de vida dos agentes patogénicos, como influencia também a própria distribuição de vetores, como insetos, caracóis ou outros animais de sangue frio. ${ }^{2,4}$

A título exemplificativo, pode realçar-se a malária, com um número superior a 400000 mortos/ano no mundo, com 216 milhões de casos no mundo em 2016, o dengue, com
96 milhões de casos no mundo em 2016, a diarreia, que mata cerca de 525000 crianças com menos de cinco anos no mundo, entre outras situações. ${ }^{5}$ De facto, é de registar a influência das alterações climáticas na distribuição e concentração de mosquitos, como o Anopheles, o Aedes Albopictus e o Aegypti, entre outros, o que influencia enormemente a distribuição das doenças infeciosas. ${ }^{6}$

O número de desastres naturais tem vindo a aumentar e é expectável que assim continue. Estes desastres resultam num valor estimado anual superior a 60000 mortos a nível mundial.

Estas ocorrências são fontes de mortes, mas também de lesões, incapacidades, doenças e alterações emocionais (não só pela perda de entes queridos, como também pelas memórias de eventos).

As inundações podem causar devastações generalizadas, com perda de vidas e danos materiais, inclusivamente nas infraestruturas de saúde. ${ }^{7}$

As inundações e os ciclones podem afetar direta/indiretamente a saúde, por aumento de casos de afogamento e traumas, riscos relacionados com o abastecimento de água e alimentos, assim como influenciar a dinâmica de distribuição e concentração de vetores. ${ }^{3,7}$ Perdas de vidas, acidentes e o pânico resultante, são aspetos a realçar.

Nalgumas zonas do globo, o aumento do nível da água do mar já levou à deslocação de pessoas das orlas costeiras, abandonando as suas habitações, para irem habitar outros locais - os refugiados climáticos.

As secas são períodos de tempo seco prolongado, que têm repercussões sobre a saúde das populações, pelo aumento da morbilidade e da mortalidade, desnutrição, devido à diminuição da disponibilidade de alimentos, risco de doenças transmissíveis, risco de doenças associadas à água, riscos associados a aglomeração de populações deslocadas e stress psicossocial e distúrbios de saúde mental.

Os incêndios provocam emissões gasosas, de extrema relevância, como gases poluentes e partículas, que podem causar problemas de saúde. O calor radiante e a inalação de fumos podem causar ferimentos graves, doenças ou morte nas pessoas diretamente expostas.

\footnotetext{
1. Unidade de Saúde Pública. Agrupamento de Centros de Saúde da Amadora. Administração Regional de Saúde de Lisboa e Vale Tejo. Portugal.

2. Professor Associado Convidado. Escola Nacional de Saúde Pública. Universidade Nova de Lisboa. Lisboa. Portugal.

$\bowtie$ Autor correspondente: António Tavares. atavares@ensp.unl.pt

Recebido: 01 de março de 2018 - Aceite: 23 de março de 2018 | Copyright @ Ordem dos Médicos 2018
} 
No que concerne às alterações ambientais emergentes, as vagas de frio, as ondas de calor, a excessiva concentração de ozono $\left(\mathrm{O}_{3}\right)$ - um importante oxidante fotoquímico - ao nível do solo, os pólenes e a poluição atmosférica são aspetos de grande relevância. A acumulação de gases com efeito de estufa na atmosfera aumenta a temperatura, causa importante de fenómenos climáticos extremos.

A acumulação de alguns produtos químicos industriais na atmosfera, em particular os CFCs, tem degradado a camada de ozono na estratosfera - barreira natural aos raios UV que atingem a Terra - dando origem a níveis de radiação ultravioleta elevados, ${ }^{1}$ com consequências nefastas para a saúde (doenças respiratórias, melanoma, o qual tem duplicado a cada 7 a 8 anos ao longo dos últimos 40 anos, envelhecimento prematuro da pele, danos na córnea, risco de cataratas e outras formas de lesão ocular) e para o ambiente (diminuição do rendimento agrícola).

Também o uso de combustíveis favorece a libertação de metano, monóxido de carbono e partículas, tendo esta poluição atmosférica efeitos na saúde. Em 2008, a exposição a níveis perigosos de poluentes no ar sob a forma de partículas finas $\left(\mathrm{PM}_{10}\right)$ foram responsáveis por 1,3 milhões de mortes prematuras em áreas urbanas.

As ondas de calor são de realçar, dada a sua elevada frequência no passado recente. O calor prolongado no Verão de 2003 na Europa, causou um aumento das taxas de mortalidade em 4 a 5 vezes os níveis esperados para aquela época do ano - registaram-se mais de 70000 mortes em excesso. De facto, $1^{\circ} \mathrm{C}$ acima de um nível limiar, pode aumentar a mortalidade em $2 \%-5 \%$, dependendo o seu impacto do nível de exposição (gravidade, frequência, duração) e da sensibilidade da população afetada. O stress térmico é mais grave nas cidades, pelo efeito de 'ilha de calor urbano' (aumento das temperaturas em mais de $5^{\circ} \mathrm{C}$ ), exacerbando os efeitos do ozono e de partículas em suspensão..$^{3,7}$

Alterações climáticas têm produzido também variações na concentração e distribuição dos pólenes e outros alérge- nos, com grandes repercussões na saúde. ${ }^{4}$ Os seus níveis são mais elevados com um calor excessivo. A prevalência de alergias relaciona-se com a presença de alergénios e o pólen no ar e as suas variações sazonais causam aumento de sintomas e do consumo de anti-histamínicos. O impacto desta situação é enorme, dado que 300 milhões de pessoas no mundo sofrem de asma e 80 milhões de europeus sofrem de várias alergias.

As alterações climáticas em curso são um desafio à escala global, com repercussões a nível das comunidades, mas também dos serviços de saúde e dos seus profissionais. ${ }^{8}$ Exigem o desenvolvimento de programas de base comunitária, através dos quais todos possamos perceber que, num pleno exercício de cidadania, a saúde se faz primeiramente em casa e na comunidade.

Todas as populações são afetadas pelas alterações climáticas, sendo algumas mais vulneráveis do que outras. As regiões costeiras, montanhosas e grandes cidades são áreas mais suscetíveis e grupos populacionais como crianças, idosos, pessoas com doenças cardiovasculares, respiratórias, oncológicas e alterações imunitárias são mais vulneráveis. Além desta análise geodemográfica, é de salientar que locais com menos infraestruturas de saúde terão menos capacidade de preparação e resposta face aos diversos cenários que podem ocorrer. ${ }^{9}$

Salienta-se a necessidade de intervenções em quatro áreas: i) criar parcerias institucionais, que incluam a saúde nas respetivas agendas das alterações climáticas; ii) promover uma adequada comunicação do risco, para reduzir a vulnerabilidade das pessoas a essas alterações; iii) desenvolver linhas de investigação que produzam evidência científica sobre as inter-relações entre as alterações climáticas e a saúde; iv) capacitar os serviços de saúde para uma adequada vigilância clínica, epidemiológica e laboratorial, que privilegie a prevenção da doença e a promoção da saúde das pessoas mais expostas e vulneráveis às mudanças climáticas.

\section{REFERÊNCIAS}

1. Merrill RM. Environmental epidemiology: principles and methods. Boston: Jones and Bartlett Publishers; 2008.

2. Wilkinson P, editor. Environmental epidemiology. New York: Open University Press; 2006.

3. Kirch W, Menne B, Bertollini R, editors. Extreme weather events and public health responses. Geneva: WHO; 2005.

4. McMichael AJ, Campbell-Lendrum DH, Corvalan CF, Ebi KL, Githeko A, Scheraga JD, et al, editors. Climate dhange and human health: risks and responses. Geneva: WHO; 2003.

5. World Health Organization. Using climate to predict infectious disease

epidemics. Geneva: WHO; 2005.

6. European Centre for Disease Prevention and Control. Environmental risk mapping: Aedes Albopictus in Europe. Stockholm: ECDC; 2013.

7. Menne B, Ebi KL, editors. Climate change and adaptation strategies for human health. Darmstadt: Steinkopff Verlag; 2006.

8. World Health Organization. Protecting health from climate change: vulnerability and adaptation assessment. Geneva: WHO; 2013.

9. World Health Organization. Operational framework for building climate resilient health systems. Geneva: WHO; 2015. 